\title{
WELCOME ADDRESS
}

Motoi Yoshioka (Dean, Graduate School of Bioresources, Mie University)

On behalf of the Faculty of Bioresources at Mie University, it is my pleasure to give these opening remarks and host the FORCOM 2011 symposium. First of all, let me express my warmest welcome to the distinguished participants, especially to the speakers who came from abroad. For the Faculty of Bioresources, where our research activities focus on international perspectives of agriculture, forestry, fisheries and food, it is quite an honor that our campus and university forest have been selected as venues for this conference. The United Nations has designated 2011 the International Year of Forests. Many related events have been, and will be, held in Japan. Research on comprehensive theory and technology related to forests is needed to make full use of the materials and environmental resources provided by forests. This includes such topics as forest ecosystems, tree physiology, sustainable control and management, and evaluation of scenery. The topics and programs listed for this conference, forest planning, resource assessment, and GIS, to name a few support these research needs, and are just right for the International Year of Forests. Personally, I have become very interested in the term "e-forest," or, forest information systems, in the recent ICT era. Several days ago, a large typhoon made landfall in Japan, severely damaging forests in Mie and neighboring Nara and Wakayama Prefectures. Our university forest was no exception. Professor MaTsumuRA, who is head of the forest station, is working with other staff members to implement recovery measures for the university forest. What we human beings can do for nature is limited, but I believe the best forest planning measures will lead to the most sustainable use of forest resources. Finally, I will conclude my opening remarks here: I look forward to fruitful discussion during this three-day conference that includes two field excursions to Odai-town and the Ise Shrine. Thank you very much for your kind attention.

\section{WELCOME ADDRESS}

Fumio Nishimura (Deputy Director General of Forest and forestry section, Department of Environment and Forestry, Mie Prefectural Government Office)

Thank you for the introduction. My name is Fumio NishimurA, and I am the Deputy Director General of the Forest and Forestry Section, Department of Environment and Forestry, Mie Prefectural Government Office. It is a pleasure to speak to you and open this International FORCOM2011 Conference. I am pleased to say, "Welcome to Mie Prefecture!" I would like to thank Dr. MATsumura and the organizing committee members for the work they have done to hold this conference at Mie University. Afforestation has been encouraged in the Mie Prefecture since the Edo period. Furthermore, intensive forest management practices like pruning and thinning have been successfully used to produce fine sugi and hinoki wood products. As a result, the proportion of plantation forest in the Mie Prefecture is about 60\%, higher than the mean value for Japan. The United Nations has proclaimed 2011 the International Year of Forests. Additionally, "the first year of forestry revitalization" has been selected as a key theme of the International Year of Forests in Japan. Last year, the government released "The Forestry Revitalization Plan," which set the target for timber self-sufficiency at over 50\% in the next decade. To achieve this goal, in April of this year forest laws were changed to reflect a new forest planning system. In the Mie Prefecture, it is a priority that sustainable forest management practices are used to increase timber production. Therefore, we need the best possible information to guide our efforts. This conference is deeply significant and timely. Scientists, researchers, and students will once again gather, to exchange information and discuss various topics about sustainable forest resources management. I hope this conference brings lively discussion and fruitful discourse. Thank you for your attention.

\section{KEYNOTE SPEECH}

Philosophy and Techniques for Forest Resource Management: Follow up and New Challenges for Coming Generations

Naoto Matsumura, Yutaka Yurugi and Shinya Numamoto (Mie University, Japan)

Ensuring the sustainability of forest resources for future generations has been a central concern for scientists and managers who have been engaged with the science and practice of forest management. Forest resources provide innumerable ecosystem services that benefit society and the environment. Effective and innovative scientific and practical methods have been developed and implemented to protect important ecosystem functions while meeting increased demands for forest products. Changing societal values demand innovative and/or integrated approaches to forest management that meet social, ecological, and economic goals. New monitoring approaches involving continuous evaluation of harvest-induced and human-induced changes in forest structure and/or function are needed. Additionally, new approaches to forest management, as well as innovative political measures, are needed to encourage the most efficient and effective use of resources. The objective of this conference is to gather state-of-the-art research results and techniques relating to the management and analysis of forest resources. The organizers would like to welcome and invite those who intend to share their ideas and thoughts about current problems in forest management with others from different regions and research areas.

\section{A Perspective on Forest Registration for the Next Generation in the Era of GIS}

Kazuhiro TANAKa (Kyoto Prefectural University, Japan)

Data of forest registration managed by prefecture are used as attribute data of forest GIS in Japan. There are some issues of data of forest registration as follows: Inadequate data on forest operation records, discrepancies with actual forest condition, insufficient data on public interest, slow pace of update, not open to the public because of private information protection, and 
so on. To overcome the above problems, required conditions of forest registration for the next generation are discussed in this paper. We need various information in forest planning, not only data of forest registration but also data of other organizations. By using spatial analysis function of GIS, we analyze various types of data such as, polygon data of forest compartment, raster data of remote sensing, point data of GPS, DEM and DSM by aircraft laser profiler. Consequently, it is recommended to keep forest data as thematic map in GIS. Present data of forest registration should be segmentalised into some thematic maps. Minimum basic data in forest GIS would be thematic map of forest physiognomy. Historical data of each forest stand would be link with forest GIS by hyperlink. Fundamental scheme of forest registration for the next generation is GIS-based structure which means that we use forest GIS as a tool of spatial analysis, not as a database.

Additional keywords: forest registration, database, forest GIS, thematic map, spatial analysis

\section{ORAL SESSION}

\section{Monitoring of Peat Swamp Forest using PALSAR Data: A Trial of Double Bounce Correction}

Yoshio AwaYA (Gifu University, Japan)

Reduction of Deforestation and Forest Degradation (REDD) is an international political issue, since about $20 \%$ of human-induced carbon emission is estimated to be caused by deforestation in the tropics. Monitoring deforestation is an important activity, since it provides basic information in REDD. Satellite remote sensing makes the monitoring possible in a large area. However, clouds disturb clear forest observation by optical sensors in tropics. Synthetic Aperture Rader (SAR) can observe the earth surface under overcastted condition from the space. Therefore SAR would provide valuable information about forest. Huge peat land forest area has been developed for rice production since latter 1990s in Central Kalimantan, Indonesia. The project caused the greatest impacts on deforestation and forest degradation in that area. There are numerous forests under declining by forest fires and reclamation still now. We aim at monitoring the peat swamp forest using ALOS/PALSAR data to demonstrate possibility of monitoring forest area by reducing the effects of double bounce on PALSAR data in open swamp forests and fire scars. Our study reviled that degradation and fragmentation continues, however, water levels in the swamp area suffered forest monitoring using PALSAR data. Although we succeeded in reducing effects of double bounce and monitoring forest changes, stand biomass was not estimated accurately. However, it would be possible to classify vegetation into about 5 classes according to biomass and to monitor deforestation.

Additional keywords: forest fire, mega rice project, backscattering coefficient

\section{Estimation of LAI and Related Metrics using Small-footprint Airborne LiDAR without a Digital Terrain Model}

Kazukiyo Yamamoto, Naoto Kondo (Nagoya University/CREST, Japan), Yoshiyuki TAKAICHI, Masashi Tsuzuki and Naoaki MuRATE (Nakanihon Air Service Co., Ltd., Japan)

The relationship between canopy structure and temporal and spatial distribution of incident understory light has been used with particular interest for evaluating the effects of silvicultural prescriptions on the survival, pattern, and diversity of understory plants and trees. Although numerous ground-based optical tools and techniques have been developed to measure various attributes of forest canopy structure and understory light environment, it is difficult to measure these attributes around the vast forested area using the ground-based methods. In our previous studies, we presented a new methodology that did not require a digital terrain model (DTM) to estimate mean tree height using small-footprint airborne LiDAR data. In this study, we applied this method to estimate the leaf area index $\left(L A I: \mathrm{m}^{2} / \mathrm{m}^{2}\right)$ and the related metrics concerning the light environment within the forest, i.e. canopy openness (CO: \%) and sky factor (SF: \%). Using the hemispherical images taken at 161 points (hereafter called for "Photo Points") within the hinoki cypress plantations and the LiDAR data, we investigated the relationship between the metrics calculated from hemispherical image (LAI, CO and $S F$ ) and the laser interception ratio (LIR: \%) calculated from LiDAR data using the method presented in our previous study. In addition, because the LiDAR-drivened metrics would be more or less scale-dependent as suggested by previous researchers, we thus compared the LIR calculated from the range $\mathrm{R}$ ( $5 \mathrm{~m}$ to $60 \mathrm{~m}$ in $5 \mathrm{~m}$ intervals) in diameters centered on a Photo Point for investigating the optimal scale to estimate the LAI, CO and SF from LiDAR data.

Additional keywords: airborne LiDAR, LAI, canopy openness, sky factor, DTM

\section{Estimating Total Biomass Carbon Stock and Carbon Absorption in Manmade Coniferous Forest Stands by Combining Low Density LiDAR and Yield Table}

Eiji KodAnI (Tohoku Research Center, Forestry and Forest Products Research Institute, Japan), Tomohiro NiSHIZONo(Forestry and Forest Products Research Institute, Japan) and Yoshio AwAYA (Gifu University, Japan)

We developed a method to estimate total biomass carbon stock and carbon absorption in manmade coniferous forest stands by combining low-density LiDAR and yield table. We established a transect 20-km long and 100-m wide that traverses the western part of Shikoku Island, Japan. Airborne LiDAR data for the transect were obtained in September 2002 by the Asahi-koyo Corporation. We set plots within the transect. The plots included non-forest areas and small to large forest stands of manmade coniferous forest of Sugi (Cryptomeria japonica) and Hinoki (Chamaecyparis obtusa), $(n=24)$. A linear regression analysis was performed between the LiDAR indices and the total biomass carbon stock. The total biomass carbon stock had the strongest relationship with the index of the last pulse average $\left(r^{2}=0.89, p=0.000\right)$. We estimated the total biomass carbon stock using the airborne LiDAR data and the regression line. Forest stand carbon absorption was estimated using a yield table (empirical growth model) with input variables of stand age from forest GIS, site index, and stand volume from the low-density LiDAR. 